\title{
A Digital Model of the Organization of Individual Reading for Students Studying Pedagogy
}

\author{
Elena O. Galitskikh* (a), Nina P. Terentyeva (b)
}

(a) Vyatka State University, e-mail: galitskiheo@rambler.ru

(b) South Ural State Humanitarian Pedagogical University, e-mail: terninapavl@yandex.ru

\begin{abstract}
The relevance of the problem of organizing individual reading for students studying pedagogy is due to the need to organize the educational process in the context of digitalization, the priority of distance learning, and students and teachers' need of feedback. The purpose of the article is to describe the experimentally developed digital model of the reader's diary of the student's individual work and to describe the results of its implementation for various pedagogical specialties. The model reveals the level of self-education, the universal way of organizing the student's own choice, study, understanding and embodiment of reading experience as a means of forming professional competencies of future teachers. Participants were 156 students of the 1st, 3rd and 5th courses of the specialty "a teacher of the Russian language and literature". The need to introduce the model is confirmed by students and teachers' positive attitude to the presented digital model, students' enthusiasm, professors' interest and personal significant results. The creative interaction of subjects of education proves the "effect of modernity" of the developed model and its relevance in the situation of online and offline education integration.
\end{abstract}

Keywords: students' individual work, activity algorithm, digital model, presentation of the reader's diary in electronic form, work stages.

(C) 2020 Elena O. Galitskikh, Nina P. Terentyeva

This is an open access article distributed under the terms of the Creative Commons Attribution License (CC BY 4.0), which permits unrestricted use, distribution, and reproduction in any medium, provided the original author and source are credited.

Published by Kazan federal university and peer-reviewed under responsibility of IFTE-2020 (VI

International Forum on Teacher Education)

\section{Introduction}

The organization of individual creative reading activity of modern students is an urgent problem of modern didactics in the context of digital education. The reader's diary has been known as a form of comprehension and internalization of information in the history of national education. The word "diary" is of French origin. It entered the lexical structure of the Russian language in the Petrine era, at the beginning of the XVIII century. It is a rip-off of a French word "journal”, formed from the noun "journee" - a day. Keeping a diary reflects the formation of personality in the context of individual and generational life.

\footnotetext{
"Corresponding author. E-mail: galitskiheo@ rambler.ru
} 
We associate the reading diary primarily with the school. The appearance of reader's diaries is connected with Jan Amos Komensky. In his speech to the gymnasium students "On the skillful use of books, the first tool for developing natural talents" (Komensky, 1991), he spoke about the importance to make extras and regular notes while reading. The reader's diary is important as a form of individual work of the reader, it shows his interests, preferences, and the personal perception of the book. Therefore, the use of the diary of individual reading at school is the most studied issue.

First-year students most often are experienced in having a traditional reading diary according to a certain plan (author, title, main characters, topic, short review).

\section{Purpose and objectives of the study}

The purpose of the study is to develop a modern model of the organization of reading compulsory and supplementary literature, works of fiction as a source of pedagogical knowledge and present the results of meaningful and creative reading in electronic original, personalized and technological forms.

\section{Literature review}

It is necessary to enrich the experience of students with modern technological methods and keeping a diary is a technological, creative and individual process.

Modern educational technologies, in particular reading and writing technology for the development of critical thinking, have many options for new formats of readers' diaries - on-board magazines (two-part, three-part diaries, which allow to generalize and systematize the flow of information; to formulate questions; to express their attitude to the topic in writing, evaluate and analyze the material; compare different points of view with each other; prove your point of view (Zaire-Bek \& Mushtavinskaya, 2004). The technology of generalization and systematization of knowledge called "List" (Galitskikh, 2016) attracts students, the diary is actively used as a reflective stage in the technology of pedagogical workshops (Galitskikh, 2016). Modern readers are interested in diaries which informally induce dialogue with the book and the author, free creative work. The format of the published "Reader's Diary" by Marta Raitses allows the reader to express his thoughts and feelings, write down favorite quotes, interesting facts, intelligence cards, reviews, fan fiction, recipes, dishes taken in the text, crosswords, illustrations (Raitses, 2017).

The era of digitalization gives rise to new electronic formats of readers' diaries, which are created using a variety of computer programs and services. Such a diary becomes a factor motivating young people to read, shaping the ability to independently select information, creative self-realization and, what is extremely important, network communication. An electronic diary may include "personal impressions of the diary owner about a book that has been read, a list of favorites, already read, or those that are planned to be read". The diary can be divided into sections, it can be arranged in the form of a table, books, presentations, scanned pictures, in the form of independently created videos posted on YouTube, your own wikipages, blogs and much more "(Alekseeva, 2013). Alekseeva (2013) notes the variability of the forms of electronic reading diaries: a reader's diary in the form of a book, in the form of advertising posters for read books, a diary in the form of travels of literary characters on a Google map, a diary of characters' destiny, a ransomware diary: a diary in tags; a diary as a time tape allows to "see the time", the reader's audio diary. 
Kvashnina (2017) writes about visualization in readers' diaries - infographics, sketching, scribing, as well as the use of signs, symbols, signals, markers. Thus, the modern reader has the opportunity to choose the form of a reader's diary traditional (paper) or electronic: it is important, «that reading should be more meaningful, that reviews should be interesting to peers, that both oral and written speech should become richer, and the creation of texts should captivate rather than cause rejection» (Kvashnina, 2017, p. 118).

Let us summarize the analysis of the diary options as ways of "undestanding yourself" and expanding your spiritual experience.

Reader diaries have different purposes and therefore, they are used differently:

Tolstoy's reading diary (2017) as a way of self-education through life;

the writer's diary as navigation, as a way of forming the literary horizons of youth. For example, Nemzer's "Reader's Diary" (2007), which appeared between 2003 and 2008, contains reviews of the most notable books and journal publications, articles on anniversaries, reports on book fairs. Petsuh's "Reader's Diary" (2006) is also an example of critical literature;

the project "Cherished dreams" by Sviridov (2008),

the diary book "What are the bestsellers talking about" (2018) of Galina Yuzefovich, the literary critic.

In these diaries the authors express a subjective evaluation of what they read and influence the tastes of the general public.

The second option, the student's diary as a form of control of his individual reading, is widely represented in the methodological literature.

The reader's diary, which is most relevant to the time and speed of the information flow, is a form of reflection of the reader of any age. The publication of reader's diaries in typography shows the popularity of this method of fixing thoughts, quotes, reading results and understanding of the text. This is a field of experimentation and pedagogical search. (Ty, 2018).

\section{Methodology}

The method of developing such a model was a long pedagogical experiment at the Faculty of Philology and Media Communications of Vyatka State University and at the Philological Faculty of South Ural State Humanitarian Pedagogical University. The experiment included 156 students of the 1st, 3rd and 5th courses of the specialty "a teacher of the Russian language and literature". We used the methods of pedagogical modeling, testing, generalization and analysis of empirical data, targeted observation of the students' individual work, the method of studying and evaluation of creative results of students' methodological and reading activities, and the method of humanitarian expertise. The experiment had two stages: the study of the motivation of the student's individual work, the study of the readers' reading experience from the standpoint of the culture of subject thinking: how they work with the text, how they save reading results, how they integrate the understanding of the text with their pedagogical and personal experience. At the second 
stage, students were to create a model of individual reading that would respond to the "challenge of the time": digitalization, personalization, globalization of professional teacher education. As a result of three years of continuous work, we have developed a model, which at the testing stage was introduced into the activities of faculties that prepare teachers of various specialties: elementary school teachers, geographers, biologists, teachers of the Russian language and literature. The pedagogical and developmental potential of the model turned out to be universal.

\section{Results}

An algorithm for organizing the reader's activity of students was developed, tested and introduced in the process of the forming experiment. The algorithm is universal and can be used in the study of any pedagogical and special disciplines. It simulates the process using the following stages of the pedagogical interaction of teachers and students with a wide information field:

Stage 1. Motivation of students for self-organization of creative reading activity as a source of professional pedagogical knowledge with the help of the workshop "An image of a modern teacher" and studying readers' diaries of outstanding teachers and literary critics.

Stage 2. Drawing up a list of sources for individual reading on the problems of an academic discipline. Focus on modern sources, problem materials, a variety of genres.

Stage 3. Students' individual reading of 10 books (articles) selected from the list and preparing materials for generalization (can be various).

Stage 4. Developing a training presentation - a digital format of a reader's diary that reveals the results according to the following frames (slides):

- a book cover, the author's abstract;

- three main quotes from the book;

- a slide with the author's ideas (from 3 to 5);

- advertising of the practical benefits of the results of reading;

- a creative task for readers, conclusion;

- experts' reviews (of a teacher, students).

Stage 5. Student's performance with the presentation of his digital reader's diary "Individual work of a student... (full name)".

Stage 6. Exchange by the results of individual reading in a student group through the creation of the group in social net VKontakte. Discussion of methodological findings, the use of ICT technologies. 
Stage 7. Reflection of personally significant results - a preparation of an analytical table in electronic format:

1. My pedagogical discoveries.

2. Readers' perspectives.

3. Pedagogical aphorisms and slogans.

The pedagogical result of this model is multidimensional: information mobility; experience of interaction, the breadth of self-education prospects and connection of "learning with life", personalization of the result, technological effectiveness of the implementation.

\section{Discussion}

Initially, the digital diary reflected the results of reading the course "Children's Literature", but when studying the course "Project Activities by the Methods of Studying Literature", students developed a digital diary "My Methodological Outlook". It has become a form of control of individual work and the subject of exchange, discussion, inclusion in NOODL seminars and forums. Thus, students and teachers developed a list of sources and mastered the content of large content of a new didactics of a modern level.

What characteristics of a digital diary as a form of individual work of students (future teachers) represent its scientific value? Digital diary as a way of organizing individual reading activities of students

- focuses students on a dialogue with the author of the book and the teacher, who makes his comment on the final slide of the digital diary;

- opens the field for creativity to a reading professor as an opportunity to see the result of his methodological lectures in student's individual reading;

- after presentations gives an opportunity to each student and teacher to see a perspective for their reading initiative;

- provides the formation of the experience of pedagogical reflection based on the plots and content of books;

- creates a feeling of "noise of time" (Barnes, 2016), "excitement of the brain" (Gerber, 1972), "collecting oneself" (Pomerantz, 2017).

132 of 156 students wrote their "Portrait of a Reader" using a digital diary, two people did not accept this form as ICT and wrote in notebooks by hand, 154 people continued to keep a digital diary after completing the course, considering it a necessary part of their professional development. The humanitarian expertise showed a high level of students' presentations. They comment on the diary, their work style, rather than voice the content of the slides. Each student is eager to make his discovery on the final slide: quote, advice, personal assessment, creative task, gift.

The value of students independence in compiling a digital reader's diary is one of the issues under discussion. To answer this question, we have built a number of arguments that convince students and even teachers of the effectiveness of such an organization of independent reading activities. 
1. The algorithm of presentation design does not allow to simply "download" information from the Internet, it must be worked out, comprehended and built.

2. An extensive list of sources in various formats: texts, articles, books, infographics, texts of "new nature", visual notes, intelligence maps, associative series, cinquaines, etc.create a space of "flow", open the horizons of creativity, freedom of choice.

3. Each defense of presentation is accompanied by a speech, which is not just about reading the content of the slides, but requires comments, bright lighting of the author's idea, and helps to reveal the identity of the student.

4. And the most important thing is that each presentation as a form of advertising of a digital reader's diary is the result, visualization of independent work, which gets its result in the presentation format, but does not exhaust it. Therefore, each author of a digital reader's diary needs to come up with a final slide with a creative task, a bright quote, and a method of reflection.

Here are five examples:

- 5th year student Anastasia Nagovitsyna told about her home library, which was started by her great-grandfather, a participant in the war, and now there are 1545 books in her library. Her photo against the background of the library decorated the final slide of her presentation.

- Master's student Kirill Karnaukhov completed his presentation with his list of promising self-educational reading.

- Yulia Pechenkina, a student, illustrated her presentation with her own drawings, original and artistic.

- Several students as a result made booktrailers for the most wonderful books of their choice.

- Creative tasks in the form were also original: profiles of modern readers

Questionnaire:

1. Tell us about a book that you read as a child and influenced the formation of your worldview.

2. What "children's" author of the twentieth century remained in your memory, and his book is considered a family heirloom?

3. What values (ideas, thoughts) of "children's literature" have passed the test of time and are preserved in the XXI century?

4. What book do you recommend to read to your young friend (student, teenager, schoolboy)?

Or reflections for the expert:

- What do you think is original or authentic in my presentation? 
- Which book, in your opinion, is the best presented?

- What do you see as the novelty element?

- Many first-year philologists decorated their presentations with quotes and tasks:

- "Yes, otherwise, many conditions are necessary for education of children's writer: it needs a gracious, loving, short, quiet, infant, innocent soul, a sublime and educated mind, an enlightened view of things, not only imagination, but also a living, poetic imagination, capable of representing all animate, rainbow images" (V. G. Belinsky). Task: list the authors who meet this assessment of the literary critic.

• "...Any kind of rudeness melts, as if on fire, under the influence of daily reading of good books " (V. Hugo) Task: what did you read today?

* "There is no substitute for a novel with a book" (D. Pennak) Task: which book did you have an affair with this semester?

\section{Conclusion}

The digital educational space creates the conditions for the search, processing and comprehension of information in the format of presentations and digital reading diaries. An important resource of a digital diary is its openness, a possibility of sharing the results of independent work among students, forming experience in presenting work results in digital format to others.

A digital model of organizing students' individual reading makes it possible to constantly update the information field in the disciplines: from "Children's literature" to "Actual problems of teaching literature." A digital reader's diary as a form of the final control of students' independent work arouses the interest of each author and the desire to make the diary individual, original, and in demand.

Students' analysis of motivational assessments of their activities proved that this mode of work is exciting, productive, and technological. It activates a cognitive interest and forms the reading culture of future teachers.

\section{References}

Alekseeva, O. S. (2013). An electronic reader diary of a pupil. School library: today and tomorrow, 2, 54-59.

Barnes, J. (2016). The Noise of Time: A Novel. Vintage.

Galitskikh, E. O. (2016). Reading with passion: workshops of life-creating. Moscow: Bibliomir.

Gerber, A. (1972). Nothing has happened. Moscow: Detskaya literatura.

Komensky, J. A. (1991). Velká didaktika: Didactica magna. Slovenské pedagogické nakladatel'stvo. 
Kvashnina, E. S. (2017). "New” children's books in the space of the library and school. New forms of organization of reader's activity. Moscow: Bibliomir.

Nemzer, A. S. (2007). Reader's diary: Russian literature in 2006. Moscow: Vremya.

Petsuh, V. A. (2006). Reader's diary. Moscow: Globulus: ENAS.

Pomerantz, G. (2017). Collecting yourself. Moscow: Centre of Humanitarian Initiatives.

Raitses, M. (2017). Reader's diary. Moscow: MYTH.

Tolstoy, L. N. (2017). Lev Tolstoy. Diaries. Notebooks. Articles. Moscow: Ikar.

Ty, E. (2018). Teaching Literatures in the Age of Digital Media. Canadian Review of Comparative Literature - Revue Canadienne de Littérature Comparée, 45(2), 213-221.

Sviridov, G.V. (2008). Cherished dreams. Moscow: "Childhood. Adolescence. Youth".

Yuzefovich, G. L. (2018). What are the bestsellers talking about. How everything works in the book world. Moscow: AST.

Zaire-Bek, S. I., \& Mushtavinskaya, I. V. (2004). The development of critical thinking in the lesson: A manual for the teacher. Moscow: Prosveshenie. 